\title{
Concept of Spinsonde for Multi-Cycle Measurement of Vertical Wind Profile of Tropical Cyclones
}

\author{
Chung-Kiak Poh, Chung-How Poh \\ Aero-Persistence Research, Penang, Malaysia \\ Email: kiak@aero-persistence.com
}

Received 1 April 2015; accepted 22 April 2015; published 24 April 2015

Copyright (C) 2015 by authors and Scientific Research Publishing Inc.

This work is licensed under the Creative Commons Attribution International License (CC BY). http://creativecommons.org/licenses/by/4.0/

(c) (i) Open Access

\begin{abstract}
Tropical cyclones and cyclogenesis are active areas of research. Chute-operated dropsondes are capable of acquiring high resolution vertical wind profile of tropical cyclones. This work proposes a chute-free vertical retardation technique (termed as spinsonde) that can accurately measure vertical wind speed profile. Unlike the expendable dropsondes, the spinsonde allows multi-cycle measurement to be performed within a single flight. Proof of principle is demonstrated via simulation and results indicate that the ground speed correlates with the wind speeds to within \pm 5 $\mathbf{k m} \cdot \mathrm{h}^{-1}$. This technique reduces flying weight and increases payload capacity by eliminating bulky chutes. Maximum cruising speed $\left(V_{H}\right)$ achieved by the spinsonde $U A V$ is $368 \mathrm{~km} \cdot \mathrm{h}^{-1}$.
\end{abstract}

\section{Keywords}

Spinsonde, Unmanned Aerial Vehicles, Tropical Cyclone, Stall-Spin Maneuver, Vertical Wind Profile

\section{Introduction}

A tropical cyclone forms over the warm ocean waters near the equator. It is a rotating storm consisting of organized system of clouds and thunderstorms and it requires a constant input of energy in the form of latent heat. Tropical cyclones often cause widespread damage when they make landfall due to high winds, torrential rainfall and storm surges [1]-[3]. In the vertical direction, winds are strongest near the surface and decay with height within the troposphere [4]. The super typhoon Haiyan that made landfall in Philippine in 2013 has sustained winds of $315 \mathrm{~km} \cdot \mathrm{h}^{-1}$ with gusts as strong as $380 \mathrm{~km} \cdot \mathrm{h}^{-1}$ [5]. Manned aircrafts have been used to fly into and around tropical cyclones at a relatively safe height of 700 mbar level (approximately $3 \mathrm{~km}$ ) to make measure- 
ments of interior barometric pressure and wind speed [6] [7]. Primary risk to manned flight is associated with downdrafts. A near-mishap occurred in 1989 when a Lockheed WP-3D Orion was flown into Hurricane Hugo [8]. Unmanned aerial vehicle (UAV) approach has been investigated to reduce risks to flight crews and to explore new capabilities. The Aerosonde has a wing span of about $3 \mathrm{~m}$ and it made its first operational flight back in 1995 [9]. It penetrated the eyewall of the typhoon Longwang on a reconnaissance observation mission in 2005 and the in situ wind measurement was consistent with the Doppler weather radar [10]. The recent Aerosonde Mark 4.7 has a dash speed of $150 \mathrm{~km} \cdot \mathrm{h}^{-1}$ at sea level [11]. NASA begun employing the Global Hawk UAVs in 2007 to study tropical cyclone using the Airborne Vertical Atmospheric Profiling System (AVAPS), or more commonly known as the dropsondes, which were developed by the U.S National Center for Atmospheric Research (NCAR) [12]. The NASA Global Hawk is ideal as it is capable of flight altitudes greater than 16,764 $\mathrm{m}$ and flight duration of up to 30 hours [12]. The expendable dropsondes is designed to be dropped from an aircraft at altitude to measure tropical cyclone conditions as it falls to the surface. From 50,000 $\mathrm{ft}(15,240 \mathrm{~m})$ down to sea level, the descent rate varied from 29.46 to $11.68 \mathrm{~m} \cdot \mathrm{s}^{-1}$ (5800 to $2300 \mathrm{ft} \cdot \mathrm{min}^{-1}$ ). The dropsondes were available in two versions, the AVAPS II sonde and the mini sonde. The mini sonde measured $30.5 \mathrm{~cm}$ in length and $4.7 \mathrm{~cm}$ in diameter, with a mass of $165 \mathrm{~g}$ and about 1000 to 1500 of them are used annually [13] [14].

Given that the dropsondes require chutes and are expendable, we hereby propose an alternative concept known as the spinsonde. It can be viewed as an integration of an UAV and a sonde. It relies on the stall-spin maneuver to slow its vertical descent and no chute is needed. The concept is illustrated using a radio control (RC) model aircraft simulation software.

\section{Materials and Methods}

\subsection{Concept of Spinsonde}

To measure the vertical wind profile, instead of deploying chutes as in the case of the dropsonde, the spinsonde UAV will execute an aerobatic maneuver known as the stall-spin to achieve retardation in the vertical descent rate. In other words, the spinsonde employs a chute-free vertical retardation technique. The main advantage is that the spinsonde UAV may exit the spin at any time, fly to another location and repeat the measurement sequence. In this way, it can acquire multiple vertical wind profile data in a single flight. Furthermore, eliminating the bulky chute will increase payload capacity.

\subsection{Simulation Details}

Simulation work was performed using the RealFlight ${ }^{\circledR *} 6.5$ simulator [15] running on a quad-core $2.2 \mathrm{GHz}$ computer. It employs RealPhysics ${ }^{\mathrm{TM}}$ technology for accurate and realistic simulations [15]. The as-supplied simulation model AR-6 Endeavor (Figure 1) was used as the RC model to demonstrate the concept of the spinsonde. The single propeller-driven AR-6 Endeavor was chosen because it is a Formula One air racer and its high cruising

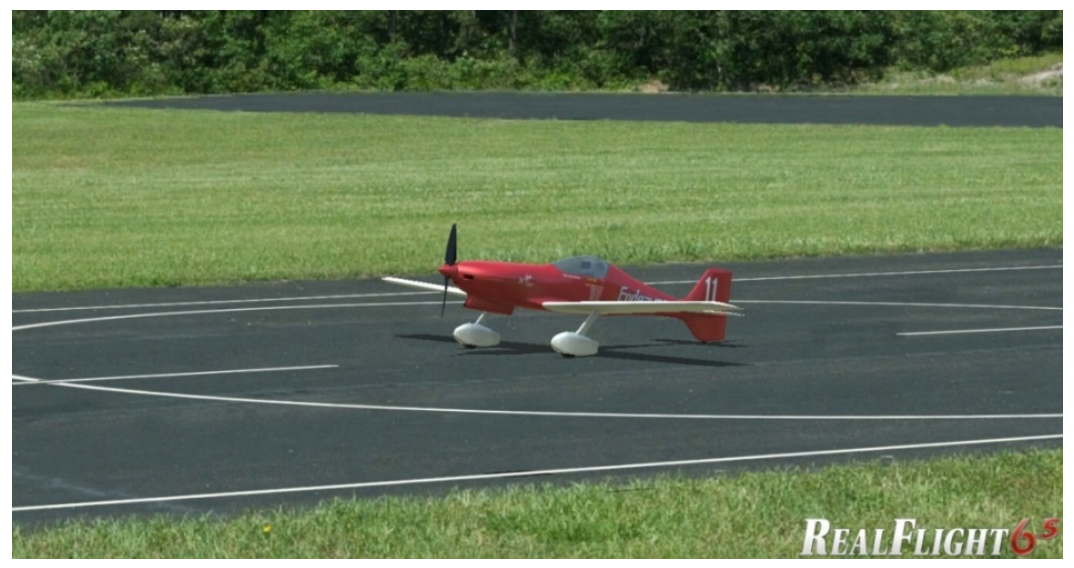

Figure 1. The AR-6 Endeavor model aircraft as supplied by the RealFlight ${ }^{\circledR}$ simulator.

${ }^{*}$ RealFlight is a registered trademark of Hobbico, Inc. used with permission. 
speed will be an advantage in transversing tropical cyclones. The Endeavor model was powered by a 2-stroke $1.60 \mathrm{cu}$ in glow engine, and it has a wing span of $2.23 \mathrm{~m}$ and flying weight of $4.96 \mathrm{~kg}$. Wing chord at root and tip were 292 and $192 \mathrm{~mm}$, respectively.

Modification of the AR-6 was done using the Accu-Model ${ }^{\mathrm{TM}}$ aircraft editor. In order to further improve the airplane's better handling of the hurricane wind conditions, the wing span was reduced to $1.94 \mathrm{~m}$ so as to increase its wing-loading. The landing gear was eliminated as well. The modified version is codenamed SP-1. Note that during simulation run, the original graphical model of AR-6 will be displayed despite physical properties (e.g. wing span) have been altered. The correct graphical model will need to be updated separately but for this simulation work it was not done as it does not affect the flight physics central to this study. Table 1 summarizes the key specifications of both aircrafts. The primary components added to the platform to enable electricpowered flight were a brushless motor and a 12-cell 16 Ah lithium polymer (Li-po) battery pack. The main advantages of employing brushless electric motor are reliability in the presence of rain water, and insensitivity to change in air pressure. 3-axis angular position dependent (roll, pitch, yaw) gyro was added to the platform for flight stabilization. The completed model weighed in at $7.91 \mathrm{~kg}$ with a wing loading of $159.8 \mathrm{~g} \cdot \mathrm{dm}^{-2}$. Flight performance and stability was evaluated under different environmental conditions.

\section{Simulation Results and Discussion}

\subsection{Level Flight and Handling Characteristics}

The SP-1 achieved a $\mathrm{V}_{\mathrm{H}}$ (maximum speed in level flight with maximum continuous power) of $368 \mathrm{~km} \cdot \mathrm{h}^{-1}$ which is faster than the sustained winds of the super typhoon Haiyan $\left(315 \mathrm{~km} \cdot \mathrm{h}^{-1}\right)$. This, in principle, would allow the SP-1 to be flown in tropical cyclones of similar strength to typhoon Haiyan. The flight stability of the platforms under strong and gusty wind conditions was performed for different wind directions: headwind, tailwind, and crosswind. The platforms were subjected to horizontal wind speed of $225 \mathrm{~km} \cdot \mathrm{h}^{-1}$, which is the maximum limit permitted by the simulator and with $100 \%$ turbulence and $30 \%$ wind gust. The control surfaces of the SP-1 were found to be responsive under these conditions with no adverse flight characteristics. Whenever there were perturbations to the roll, pitch and yaw angles, the onboard 3-axis heading hold gyro would attempt to steer them back. No inherent flight control instability was observed. Furthermore, the SP-1 was more resistant to turbulence than the AR-6 due to its higher wing loading.

\subsection{Spinsonde and Vertical Wind Speed Profile Measurement}

Chutes were used in the dropsondes to slow their vertical descent rate and the descent rate of the dropsondes close to sea-level was $11.68 \mathrm{~m} \cdot \mathrm{s}^{-1}$. This section investigates the effectiveness of spinsonde technique in measuring the wind profile. Eliminating the bulky chute will increase payload capacity and more importantly, enable the vertical descent sequence to be repeated multiple times per flight. The SP-1 was deliberately entered into a stall to initiate the maneuver. The steady-state stall-spin was achieved by applying full deflection of rudder and aileron in the same direction and applying up elevator. The angular displacements of all three control surfaces were approximately $45^{\circ}$. The maneuver was performed under $500 \mathrm{~m}$ altitude and the descent rate was found to be $11.2 \mathrm{~m} \cdot \mathrm{s}^{-1}$, as indicated by the variometer as shown in Figure 2. The stall-spin could be terminated by returning the control surfaces to neutral position and pulling up on the elevator to resume horizontal flight.

To investigate the ability of the technique to reliably detect wind speed, the stall-spin maneuver for the SP-1 was repeated with various horizontal wind speeds. Turbulence and gust were turned off in order to evaluate the effect reliably. One could observe the platform drifting in the lateral direction with the wind. Figure 3(a) and Figure 3(b) show the drifting in wind speed of $50 \mathrm{~km} \cdot \mathrm{h}^{-1}$ and $180 \mathrm{~km}^{-1}$, respectively. Ground speeds were found to closely match the wind speeds to within $\pm 5 \mathrm{~km} \cdot \mathrm{h}^{-1}$. This simulation work provided evidence that the stall-spin maneuver can be used as substitution for chute. Videos showing the stall-spin maneuvers of the SP-1

Table 1. Specifications for the as-supplied AR-6 and the SP-1.

\begin{tabular}{ccccc}
\hline Aircraft model & Flying weight $(\mathrm{kg})$ & Fuselage width $(\mathrm{m})$ & Wing span $(\mathrm{m})$ & Wing $l o a d i n g\left(\mathrm{~g} \cdot \mathrm{dm}^{-2}\right)$ \\
\hline AR-6 & 4.96 & 0.251 & 2.23 & 89.1 \\
SP-1 & 7.91 & 0.200 & 1.94 & 159.8 \\
\hline
\end{tabular}




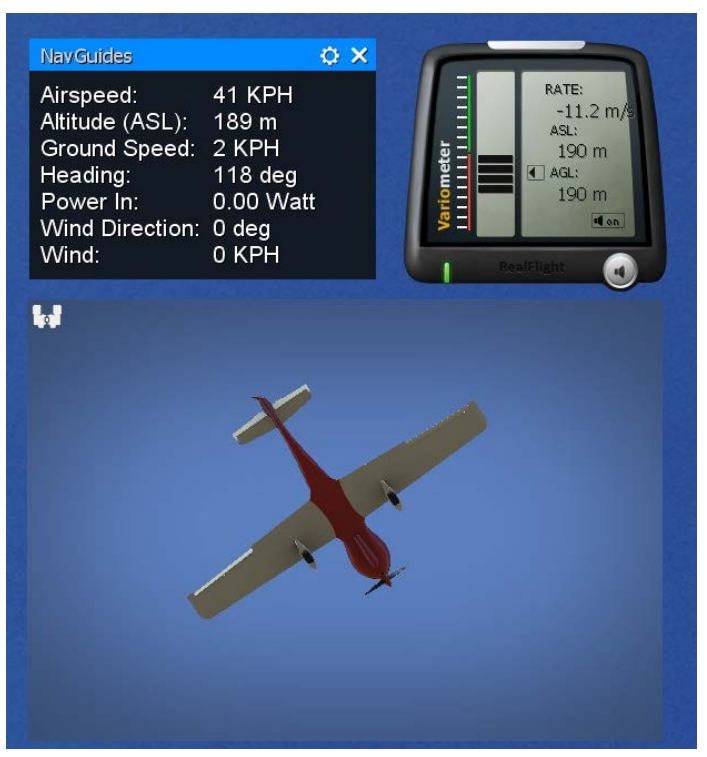

Figure 2. Dynamic parachuting: stall-spin maneuver performed by the SP-1 with the variometer showing a descent rate of $11.2 \mathrm{~m} \cdot \mathrm{s}^{-1}$. Full deflection of the control surfaces can also be observed.

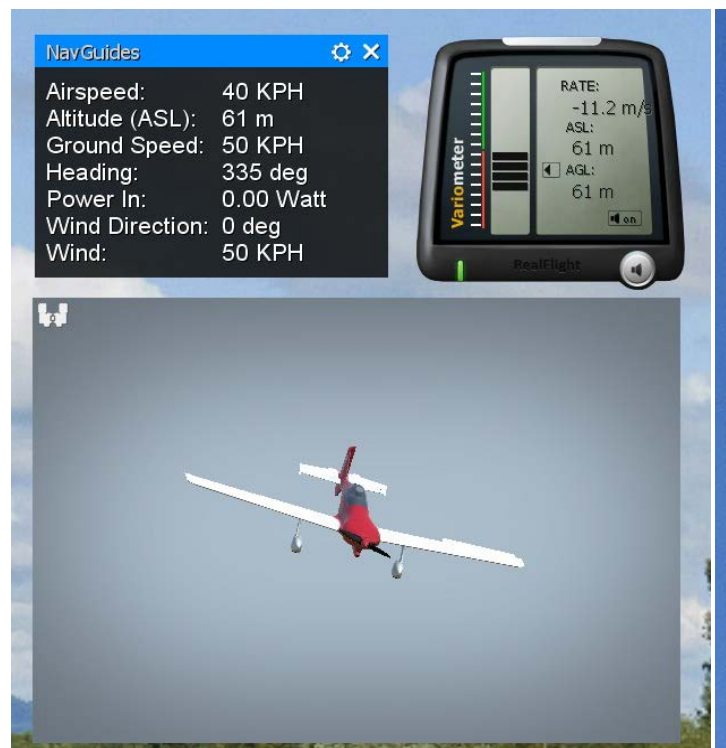

(a)

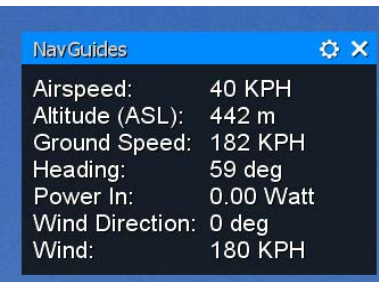

If

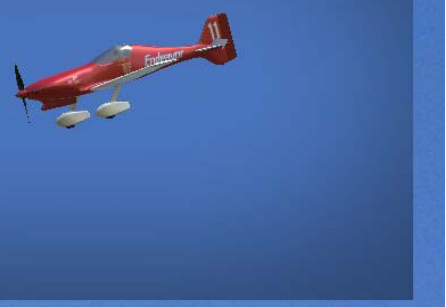

(b)

Figure 3. SP-1 performing the stall-spin maneuver amidst wind of intensity (a) $50 \mathrm{~km} \cdot \mathrm{h}^{-1}$ and (b) $180 \mathrm{~km} \cdot \mathrm{h}^{-1}$. The ground speeds were found to correlate strongly with the wind intensities to within $\pm 5 \mathrm{~km} \cdot \mathrm{h}^{-1}$.

including the exit to level flight in still air and strong wind are available as ancillary files (1 and 2, respectively). Also, it can be observed from the movie files that the axis of rotation of the stall-spin is close to the center of gravity of the aircraft and, therefore the maneuver is not expected to affect the empirical GPS speed measurement as the sub-meter variation is smaller than the resolution of GPS for civilian applications.

To evaluate the effects of the parameters of the airframe on the stall-spin descent rate and the $\mathrm{V}_{\mathrm{H}}$, two variations of the SP-1 model were created and they were codenamed SP-0 and SP-2. The evaluated parameters were the wing span and the fuselage width, as tabulated in Table 2. The SP-2 with a wing span of only $80 \mathrm{~cm}$ and a fuselage width of $12 \mathrm{~cm}$ achieved a $\mathrm{V}_{\mathrm{H}}$ of $400 \mathrm{~km} \cdot \mathrm{h}^{-1}$ which is higher than the wind gust of super typhoon Hai- 
Table 2. Summary of maximum cruising speed $\left(\mathrm{V}_{\mathrm{H}}\right)$ and stall-spin vertical descent rate for SP-1 and its variants.

\begin{tabular}{ccccc}
\hline Aircraft model & Wing span $(\mathrm{cm})$ & Fuselage width $(\mathrm{cm})$ & Stall-spin descent rate $\left(\mathrm{m} \cdot \mathrm{s}^{-1}\right)$ & $\begin{array}{c}\text { Maximum cruising speed } \\
\left(\mathrm{km} \cdot \mathrm{h}^{-1}\right)\end{array}$ \\
\hline SP-0 & 300 & 25 & 7.5 & 350 \\
SP-1 & 194 & 20 & 11.2 & 368 \\
SP-2 & 80 & 12 & 16.8 & 400 \\
\hline
\end{tabular}

${ }^{\mathrm{a}}$ Descent rate of chute-operated dropsonde near sea-level is $11.68 \mathrm{~m} \cdot \mathrm{s}^{-1}$.

yan $\left(380 \mathrm{~km} \cdot \mathrm{h}^{-1}\right)$. However, its relatively short wing resulted in a high stall-spin descent rate of $16.8 \mathrm{~m} \cdot \mathrm{s}^{-1}$. The SP-0, on the other hand, has a stall-spin descent rate of only $7.5 \mathrm{~m} \cdot \mathrm{s}^{-1}$ which is much slower than that of dropsondes (11.68 m·s ${ }^{-1}$ at near sea level). SP-0 has a $V_{H}$ of only $350 \mathrm{~km} \cdot \mathrm{h}^{-1}$ but it is nevertheless higher than the typhoon Haiyan's sustained wind speed of $315 \mathrm{~km} \cdot \mathrm{h}^{-1}$. Given the simulated results in Table 2, the SP-1 can be considered as a typhoon UAV having the optimum parameters and characteristics to fly into the storm and to carry out the vertical wind profile measurements.

While the expendable dropsonde can record vertical wind speed profile all the way to the surface of the ocean, the minimum time required to pull the aircraft out of the stall-spin in piloted mode was typically $3 \mathrm{~s}$. This implied that the SP-0 has to exit the stall-spin no less than $22.5 \mathrm{~m}$ above sea level. Similarly, SP-1 and SP-2 will require altitudes of 33.6 and $50.4 \mathrm{~m}$, respectively. Possible methods of improvements are to reduce the wing loading of these aircraft and to develop algorithms to enable the UAV to exit the stall-spin efficiently and in the shortest amount of time. If they can be accomplished, then the $10 \mathrm{~m}$ surface wind can readily be included in the vertical wind speed profile.

\section{Conclusion}

This work proposed and demonstrated via simulation the concept of spinsonde. It represents a chute-free technique applicable to UAV and is capable of performing vertical wind speed profile measurement within and around tropical cyclones. In still air, the simulated spinsonde UAV achieved a maximum cruising speed $\left(\mathrm{V}_{\mathrm{H}}\right)$ of $368 \mathrm{~km} \cdot \mathrm{h}^{-1}$. The proposed stall-spin maneuver was found to be an effective substitution for chute with the ability to carry out multi-cycle measurement at various target locations compared to the current expendable dropsonde method. Elimination of the chute also increases payload mass and volume. The technique of spinsonde will open a new chapter in tropical cyclone research.

\section{References}

[1] Cheung, K.K.W., Chang, L.T.C. and Li, Y. (2014) Rainfall Prediction for Land Falling Tropical Cyclones: Perspectives of Mitigation. Typhoon Impact and Crisis Management. Series: Advances in Natural and Technological Hazards Research. Springer Berlin Heidelberg.

[2] Doocy, S., Dick, A., Daniels, A. and Kirsch, T.D. (2013) The Human Impact of Tropical Cyclones: A Historical Review of Events 1980-2009 and Systematic Literature Review. PLOS Currents Disasters.

[3] Chan, J.C.L. and Kepert, J.D. (2010) Global Perspectives on Tropical Cyclones: From Science to Mitigation. World Scientific Publishing Co. Pte. Ltd., Singapore City. http://dx.doi.org/10.1142/7597

[4] Frank, W.M. (1977) The Structure and Energetics of the Tropical Cyclone I. Storm Structure. Monthly Weather Review, 105, 1119-1135. http://dx.doi.org/10.1175/1520-0493(1977)105\%3C1119:TSAEOT\%3E2.0.CO;2

[5] Mortillaro, N. (2013) Why Super Typhoon Haiyan Was so Destructive. http://globalnews.ca/news/955086/why-super-typhoon-haiyan-was-so-destructive/

[6] Hurricane Hunter Association (2014) The History of the Hurricane Hunters. http://www.hurricanehunters.com/history.htm

[7] Patricia and Phillip Frost Museum of Science (2015) Inside a Hurricane. http://www.miamisci.org/hurricane/plane.html

[8] Masters, J. (2014) Hunting Hugo. http://www.wunderground.com/resources/education/hugo1.asp

[9] Holland, G.J. (2001) The Aerosonde Robotic Aircraft: A New Paradigm for Environmental Observations. Bulletin of the American Meteorological Society, 82, 889-901. http://dx.doi.org/10.1175/1520-0477(2001)082<0889:TARAAN>2.3.CO;2

[10] Lin, P.H. and Lee, C.S. (2008) The Eyewall-Penetration Reconnaissance Observation of Typhoon Longwang (2005) 
with Unmanned Aerial Vehicle, Aerosonde. Journal of Atmospheric and Oceanic Technology, 25, 15-25. http://dx.doi.org/10.1175/2007JTECHA914.1

[11] AAI Corp (2010) Aerosonde Mark 4.7: Redefining Expeditionary. http://www.aerosonde.com/pdfs/aerosonde-mark-47.pdf

[12] NASA (2014) HS3 Hurricane Mission.

http://www.nasa.gov/mission_pages/hurricanes/missions/hs3/

[13] Hock, T. (2012) NCAR/NSF GV New Automated Dropsonde System Overview. http://www.eol.ucar.edu/projects/mpex/meetings/2012Dec/presentations/04_Hock.pdf

[14] Wikipedia (2013) Dropsonde. http://en.wikipedia.org/wiki/Dropsonde

[15] Great Planes ${ }^{\circledR}$ Model Mfg (2014) RealFlight ${ }^{\circledR}$ Radio Control Flight Simulator. http://www.realflight.com/ 